\title{
Activity of Thalamic Reticular Neurons during Spontaneous Genetically Determined Spike and Wave Discharges
}

\author{
Seán J. Slaght, ${ }^{1}$ Nathalie Leresche, ${ }^{2}$ Jean-Michel Deniau, ${ }^{3}$ Vincenzo Crunelli, ${ }^{1}$ and Stéphane Charpier ${ }^{3}$ \\ ${ }^{1}$ School of Biosciences, Cardiff University, Cardiff CF10 3US, United Kingdom, 2Neurobiologie des Processus Adaptatifs, \\ Université Pierre et Marie Curie, F-75005 Paris, France, and ${ }^{3}$ Chaire de Neuropharmacologie, Institut National de la Santé \\ et de la Recherche Médicale Unité 114, Collège de France, 75231 Paris, France
}

This study reports the first intracellular recordings obtained during spontaneous, genetically determined spike and wave discharges (SWDs) in nucleus reticularis thalami (NRT) neurons from the genetic absence epilepsy rats from Strasbourg (GAERS), a model that closely reproduces the typical features of childhood absence seizures.

A SWD started with a large hyperpolarization, which was independent of the preceding firing, and decreased in amplitude but did not reverse in polarity up to potentials $\geq-90 \mathrm{mV}$. This hyperpolarization and the slowly decaying depolarization that terminated a SWD were unaffected by recording with $\mathrm{KCl}$ filled electrodes. The prolonged (up to 15 action potentials), high-frequency bursts present during SWDs were tightly synchronized between adjacent neurons, correlated with the EEG spike component, and generated by a low-threshold $\mathrm{Ca}^{2+}$ potential, which, in turn, was brought about by the summation of high-frequency, small-amplitude depolarizing potentials.
Fast hyperpolarizing IPSPs were not detected either during or in the absence of SWDs. Recordings with $\mathrm{KCl}$-filled electrodes, however, showed a more depolarized resting membrane potential and a higher background firing, whereas the SWDassociated bursts had a longer latency to the EEG spike and a lower intraburst frequency. This novel finding demonstrates that spontaneous genetically determined SWDs occur in the presence of intra-NRT lateral inhibition.

The unmasking of these properties in the GAERS NRT confirms their unique association with spontaneous genetically determined SWDs and thus their likely involvement in the pathophysiological processes of the human condition.

Key words: cortex; thalamus; burst firing; GAERS; absence epilepsy; lateral inhibition
Childhood absence epilepsy (CAE) is a generalized epilepsy of multifactorial genetic origin (Panayiotopoulos, 1997). Experimental studies (Avoli et al., 1990, 2001; Snead, 1995) have demonstrated the involvement of the GABAergic neurons of the nucleus reticularis thalami (NRT) in the generation of spike and wave discharges (SWDs), the EEG hallmark of absence seizures. In particular, lesions of, or $\mathrm{Cd}^{2+}$ injections in, the NRT block SWDs in genetic absence epilepsy rats from Strasbourg (GAERS) (Avanzini et al., 1993), an inbred genetic model of CAE (Marescaux et al., 1992). Moreover, NRT but not thalamocortical neurons from preseizure GAERS show a larger T-type $\mathrm{Ca}^{2+}$ current than nonepileptic control rats (Tsakiridou et al., $1995)$ and an increased mRNA expression of $\alpha 1$ (Talley et al., 2000), one of the T-type $\mathrm{Ca}^{2+}$ channel subunits (Lee et al., 1999). Finally, intra-NRT injection of $\mathrm{GABA}_{\mathrm{B}}$ agonists aggravates absence seizures in every CAE model, whereas $\mathrm{GABA}_{\mathrm{B}}$ antagonists abolish them (Hosford et al., 1992; Liu et al., 1992; Snead, 1992).

Although our understanding of the pathophysiological mechanisms operating in the NRT during SWDs has been greatly

\footnotetext{
Received Nov. 5, 2001; revised Dec. 27, 2001; accepted Dec. 26, 2001.

This work was supported by Wellcome Trust Grant 37089-98, by European Union Grant 97-2093, and by the Ministere Français de la Recherche (Action Concertée d'Initiative Biologie du Développement et Physiologie Intégrative 2000). S.J.S. is a Wellcome Prize Student. We thank Dr. S. W. Hughes, S. Mahon, and Dr. H. R. Parri for critical discussions on the experiments and comments on this manuscript and A. Menetrey for assistance with the histological processing.

Correspondence should be addressed to V. Crunelli, School of Biosciences, Cardiff University, Museum Avenue, Cardiff CF10 3US, UK. E-mail: crunelli@cardiff.ac.uk. Copyright (C) 2002 Society for Neuroscience $0270-6474 / 02 / 222323-12 \$ 15.00 / 0$
}

advanced by recent in vivo and in vitro studies, difficulties exist in the interpretations of these results, because most of the model systems used do not fully reproduce the CAE seizure properties. In particular:

(1) The in vivo recorded, spontaneous (and electrically or bicuculline-induced) $2-4 \mathrm{~Hz}$ spike/polyspike-wave complexes in cats are often accompanied by "fast runs" (10-15 Hz) and postictal depression (Steriade and Contreras, 1995; Neckelmann et al., 1998; Timofeev et al., 1998), which are absent in CAE. Furthermore, the spontaneity of these $2-4 \mathrm{~Hz}$ paroxysms appears to be linked to repeated electrical stimulation more than to a genetic predisposition (Steriade and Contreras, 1998; Steriade et al., 1998).

(2) The in vitro studies, either in the ferret perigeniculate nucleus (PGN) (the visual segment of the NRT) after application of bicuculline (Bal et al., 1995a,b) or in the NRT of transgenic mice lacking intra-NRT GABA ${ }_{\mathrm{A}}$-mediated inhibition (Huntsman et al., 1999), assume that the pharmacological or transgenic block of $\mathrm{GABA}_{\mathrm{A}}$ inhibition within an isolated thalamus reproduces the thalamic network activity underlying SWDs. Intrathalamic application of bicuculline, however, does not elicit SWDs in the thalamus of decorticated animals (Steriade and Contreras, 1998). Furthermore, the addition of an "artificial" corticothalamic feedback to the in vitro thalamic network (Bal et al., 2000; Blumenfeld and McCormick, 2000) produces in thalamocortical neurons a low-threshold $\mathrm{Ca}^{2+}$ potential (LTCP) at each cycle, whereas LTCPs are only occasionally observed in vivo (Steriade and Contreras, 1995; Pinault et al., 1998). 
(3) The sensitivity of these in vivo and in vitro paroxysms to anti-absence medicines is unknown.

Thus, because some mechanisms underlying NRT neuron activity during SWDs may not have been fully elucidated because of the peculiar features of the models used, we have now made in vivo extracellular and intracellular recordings from NRT neurons in GAERS, a model that closely reproduces the spontaneity, EEG waveform, behavioral component, and pharmacological profile of CAE seizures (Marescaux et al., 1992). Preliminary data have been published previously (Slaght et al., 2000).

\section{MATERIALS AND METHODS}

All experiments were performed in accordance with local ethical committee and European Union guidelines (directive 86/609/EEC), and every precaution was taken to minimize suffering to the animals and the number of animals used in each experiment.

Surgery. Experiments were conducted as described previously (Pinault et al., 1998; Charpier et al., 1999). Briefly, adult (4- to 5-month-old) male and female rats from the GAERS strain were initially anesthetized with pentobarbital (Sanofi, Libourne, France) $(40 \mathrm{mg} / \mathrm{kg}$, i.p.) and ketamine (Imalgène, Rhone Mérieux, France) (100 mg/kg, i.m.), and a cannula was placed into the trachea before they were positioned in a stereotaxic frame. All wounds and pressure points were infiltrated with Xylocaine $2 \%$ (Astra, Neuilly, France) (repeated every $2 \mathrm{hr}$ ) while body temperature was maintained $\left(36.5-37.5^{\circ} \mathrm{C}\right)$ with a homeothermic blanket (Harvard Apparatus Ltd, Edinbridge, UK). Once the surgical procedures had been completed, neurolept-anesthesia was initiated with an injection of Fentanyl (Janssen, Issy-Lef-Moulineiux, France) ( $3 \mu \mathrm{g} / \mathrm{kg}$, i.v.) and haloperidol (Haldol; Janssen, France) $(1 \mathrm{mg} / \mathrm{kg}$, i.p.) that was repeated every 20-30 min (Flecknell, 1996). To obtain long-lasting stable intracellular recordings, rats were immobilized with gallamine triethiodide (Flaxedil, Specia, Paris, France) (40 mg, i.m., repeated every $2 \mathrm{hr}$ ) and artificially ventilated. The degree of anesthesia was assessed by continuously monitoring the EEG and heart rate, and additional doses of anesthetic were administered at the slightest change toward an awake pattern (i.e., an increase in the frequency and reduction in the amplitude of the EEG waves and/or an increase in heart rate). At the end of the experiments, animals received an overdose of pentobarbital and were transcardially perfused as described below.

Recordings and data analysis. EEG recordings were obtained with a silver monopolar electrode placed on the dura above the orofacial motor cortex (12 $\mathrm{mm}$ anterior to the interaural line, $3.5-4 \mathrm{~mm}$ lateral to the midline). A reference electrode was placed in the muscle to the side of the head. For extracellular recordings and juxtacellular labeling, glass electrodes were filled with $0.5 \mathrm{M} \mathrm{NaCl}$ and $1.5 \%$ neurobiotin (Vector Laboratories, Burlingame, CA) (15-20 M $\Omega$ ). Intracellular recordings were obtained with glass electrodes containing $1.5 \%$ neurobiotin and $2 \mathrm{M}$ $\mathrm{KAc}(45-85 \mathrm{M} \Omega)$ or $3 \mathrm{M} \mathrm{KCl}(30-40 \mathrm{M} \Omega)$. Stereotaxic coordinates for NRT recordings were $7-7.5 \mathrm{~mm}$ anterior to the interaural line, $2.4 \mathrm{~mm}$ lateral to the midline, and $4.5-6.5 \mathrm{~mm}$ ventral to the brain surface (Paxinos and Watson, 1986). NRT units showed a monosynaptic response to motor cortex stimulation, were antidromically activated by stimulation of the ventrolateral nucleus, and were characterized by short-duration action potentials and an accelerating-decelerating pattern in LTCP-elicited bursts of action potentials (Mulle et al., 1986; Spreafico et al., 1988; Avanzini et al., 1989; Bal and McCormick, 1993; Contreras et al., 1993).

Extracellular and intracellular recordings were obtained using the active bridge mode of an Axoclamp 2B amplifier (Axon Instruments, Foster City, CA), filtered at $0.3-3$ and $30 \mathrm{kHz}$, respectively, and stored on a Biologic DAT recorder (Intracel, Royston, UK). Data were subsequently digitized at $40 \mathrm{kHz}$ (intracellular/extracellular) or $2 \mathrm{kHz}$ (EEG) for off-line analysis with Spike2 software (Cambridge Electronic Design, Cambridge, UK).

The dominant frequency of the EEG during SWD was calculated by successive fast Fourier transforms using the Power Spectrum tool in Spike2. The start and end of a SWD in the EEG were taken to be the first and last spike-wave complexes, respectively, where the size of the spike was at least three times the peak-to-peak amplitude of the baseline EEG. Cross-correlograms of the firing between two units of a multiunit recording were obtained by first encoding the position of the peak of the action potentials into separate event channels using the memory buffer function of Spike2; the event correlation function of Spike2 (width, 2 sec; bin size,
$5 \mathrm{msec}$ ) was then used to produce the cross-correlogram for $10 \mathrm{sec}$ periods either during or between SWDs.

The apparent input resistance of NRT neurons was measured by averaging at least 10 voltage responses to hyperpolarizing current pulses $(0.2-0.5 \mathrm{nA}, 100 \mathrm{msec})$. The action potential properties (afterhyperpolarization, duration at threshold, and half-width) were obtained by averaging at least 50 action potentials recorded at resting membrane potential. The amplitude of the afterhyperpolarization was measured from the resting potential to its peak amplitude, whereas the time to peak was calculated from the point at which the downstroke of the action potential crossed the resting potential.

Statistical significance was assessed using Student's $t$ test for comparison between two groups, and one-way ANOVA with all pairwise comparisons for analysis among three or more groups. Some data were fitted to a Gaussian-Laplace distribution using the Gaussian fit function of Origin 6.0 (Microcal Software Inc, Northampton, MA) after the normality of their distribution had been tested with the Kolmogorov-Smirnov test. Quantitative data are presented throughout as mean $\pm \mathrm{SD}$, unless stated otherwise.

Neuron visualization. Extracellularly recorded neurons were labeled using juxtacellular injection of neurobiotin (Pinault, 1996; Mailly et al., 2001). Briefly, at the end of the recording session, positive current pulses $(1-8 \mathrm{nA}, 200 \mathrm{msec})$ were applied at a frequency of $2.5 \mathrm{~Hz}$ through the bridge circuit of the amplifier. The current was slowly increased while the electrode was advanced toward the neuron by $1 \mu \mathrm{m}$ steps until the cell discharge was driven by the injected current. Current pulses were applied for a $10-15 \mathrm{~min}$ period to obtain a reliable labeling of neuronal processes. For intracellular recordings, depolarizing current pulses $(0.2-1$ $\mathrm{nA}, 100-200 \mathrm{msec}$ ) were applied at a frequency of $2.5 \mathrm{~Hz}$ at the end of the recording period.

At $1-2 \mathrm{hr}$ after the injection, the animal received a lethal dose of pentobarbital and was perfused via the ascending aorta with $200 \mathrm{ml}$ of saline followed by $500 \mathrm{ml}$ of $0.3 \%$ glutaraldehyde and $4 \%$ paraformaldehyde in phosphate buffer (PB), 0.1 M, pH 7.4. Brains were post-fixed for $2 \mathrm{hr}$ in the same fixative solution without glutaraldehyde and then immersed in $20 \%$ sucrose $\mathrm{PB}$ at $4^{\circ} \mathrm{C}$ until sectioning. Frozen sections of fixed brains were cut at $50-70 \mu \mathrm{m}$ in the frontal plane and serially collected in PB. After several rinses in PB, neurobiotin was revealed by incubation of the sections in the avidin-biotin peroxidase complex (1: 100; Vector Laboratories) in PB containing $0.3 \%$ Triton X-100 for at least $12 \mathrm{hr}$ at $4^{\circ} \mathrm{C}$. Incubated sections were washed in PB (two times for $10 \mathrm{~min}$ ) before immersion in a solution containing $0.05 \% 3,3^{\prime}$ diaminobenzidine tetrahydrochloride (Sigma, St. Louis, MO), 0.4\% nickel-ammonium sulfate, and $0.0006 \% \mathrm{H}_{2} \mathrm{O}_{2}$. After several washes in $\mathrm{PB}$, sections were mounted on gelatin-coated slides, counterstained with safranin, and dehydrated through alcohol to xylene for light microscopic examination. The position of labeled neurons within the NRT was confirmed using the atlas of Paxinos and Watson (1986).

\section{RESULTS}

The results of this study are based on 18 extracellularly and 16 intracellularly recorded NRT neurons. Eleven (of 13 injected) neurons were recovered after intracellular $(n=7)$ or juxtacellular $(n=4)$ injection of neurobiotin. These neurons were located in the rostral portion of the NRT (see Figs. 1 $A 2,9 A 2$ ), were scattered throughout its dorsoventral extent, and had morphological features similar to those described previously (Ohara and Lieberman, 1985; Spreafico et al., 1988; Steriade et al., 1997). In particular, they presented either an ovoid (fusiform) or polygonal perikaryon and were characterized by a number of varicose dendrites (see Fig. 9A3). The axon emerged from the perikaryon or from a proximal dendrite and coursed caudally and medially, forming a well defined terminal field in ipsilateral relay nuclei (seven in the ventrobasal complex, two in the posterior nucleus, and one in the laterodorsal nucleus). These axonal projections followed a dorsoventral topography, with cells located in the dorsal portion of the NRT innervating dorsal portions of the relay nuclei.

The properties of the SWDs recorded by the EEG electrode were identical to those described previously in vivo under similar experimental conditions (Pinault et al., 1998; Seidenbecher et al., 
A1

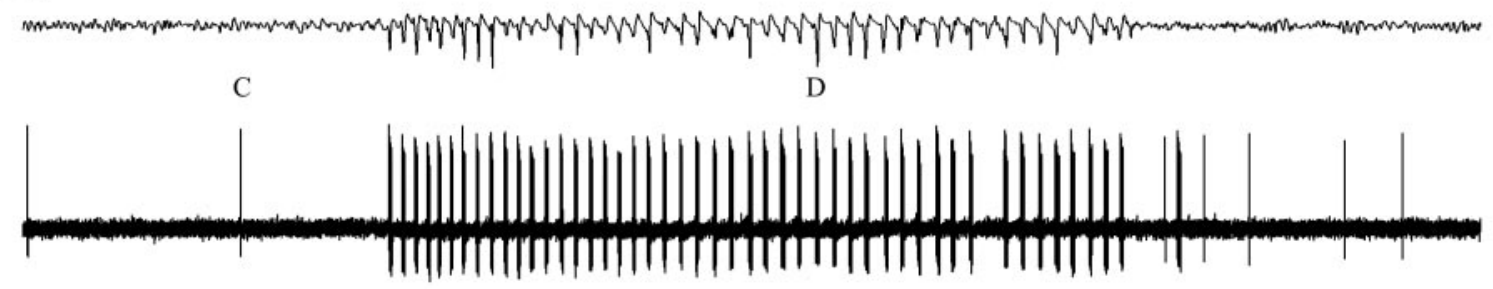

B

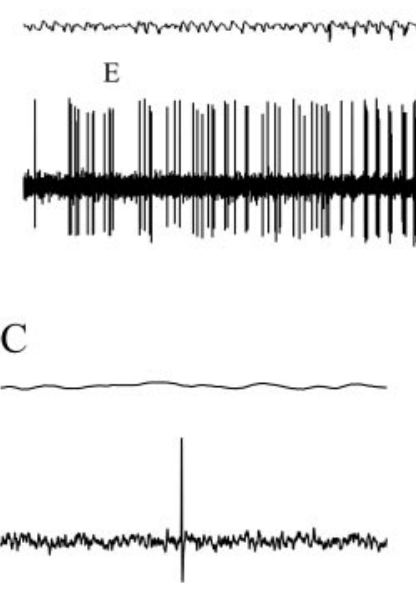

$2 \mathrm{sec}$

$\mathrm{F}$

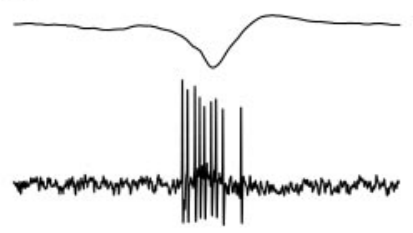

$\mathrm{E}$

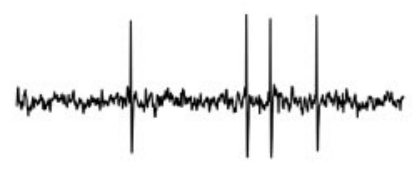

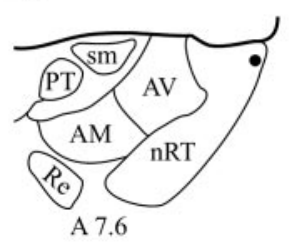

A3

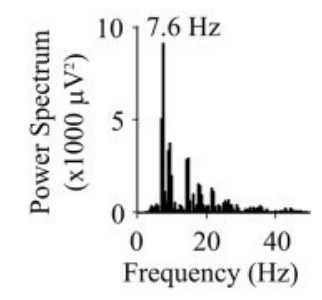

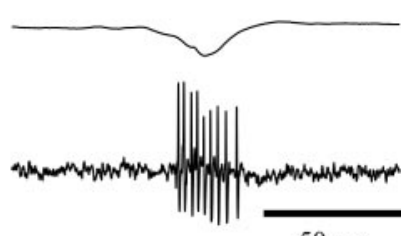

$50 \mathrm{~ms}$

Figure 1. Extracellularly recorded activity of NRT neurons during SWDs. A1, The very occasional single spike firing of this unit (bottom trace), recorded in the rostral pole of the NRT ( filled circle in $A 2$, schematic horizontal plane drawing), becomes a high-frequency burst pattern concomitantly with the appearance of the first spike-wave complex in the EEG (top trace). The burst firing continues for the entire duration of the SWD, matching all but one spike-wave complex. A marked single spike and burst are enlarged in $C$ and $D$, below. $A 3$, A power spectrum shows the dominant frequency (indicated) of the SWD in $A 1$. B, The background firing of this unit (a mixture of single spikes and short bursts) is transformed to high-frequency bursts after four spike-wave complexes are visible in the EEG (top trace). Marked firing before and during the SWD is enlarged in $E$ and $F$, below. Time calibration in $B$ and $F$ also applies to $A 1$ and $C-E$, respectively. $A M$, Anteromedial thalamic nucleus; $A V$, anteroventral thalamic nucleus; $n R T$, thalamic reticular nucleus; $P T$, parathenial thalamic nucleus; Re, reunions thalamic nucleus; sm, stria medullaris. Anteriority relative to the interaural line is indicated (Paxinos and Watson, 1986). In this and all following figures, the top trace in each pair is the EEG, and the bottom trace is the simultaneously recorded extracellular or intracellular voltage (unless stated otherwise).

1998; Charpier et al., 1999; Seidenbecher and Pape, 2001) and in freely moving GAERS (Marescaux et al., 1992). Thus, the duration of SWDs ranged from $800 \mathrm{msec}$ to $3 \mathrm{~min}$, and even in the same animal, we could observe from a few short SWDs per minute up to a SWD every $5 \mathrm{~min}$. The intra-SWD frequency ranged from 7 to $9 \mathrm{~Hz}$ (Fig. 1A3).

\section{Extracellular recordings}

Single NRT units showed different patterns of background firing (Fig. 1A1,B); these patterns included electrical silence, single action potentials (Fig. $1 A 1, C$ ), short bursts of action potentials, or a mixture of short bursts and single action potentials (Fig. 1B,E). The single action potential firing frequency ranged from 1 to 43 $\mathrm{Hz}$, and the bursts contained $5.6 \pm 3.4$ action potentials $(n=10$ $\mathrm{U})$, had an intraburst frequency of $216 \pm 41 \mathrm{~Hz}$, and recurred once every $0.01-10 \mathrm{sec}$.

When a SWD appeared in the EEG, the firing of all NRT units drastically changed as it became exclusively characterized by prolonged, high-frequency action potential bursts (Fig. 1D,F), which occurred at the same frequency as the SWD in the EEG (Fig. 1A3). The start (and end) of the paroxysmal activity in NRT neurons relative to the start (and end) of the corresponding SWD in the EEG was variable. Analysis of 50 representative SWDs from $5 \mathrm{U}$ indicated that the shift to the distinctive high-frequency burst firing started after the appearance of the first clearly defined spike-wave complex in the EEG in $56 \%$ of SWDs (Fig. $1 B$ ), before the first spike-wave complex in $22 \%$ of cases, and at the same time in the remaining 22\% (Fig. 1A1). These different possibilities could be present in successive SWDs within the same unit. When the neuron did not start to burst at the same time as the first spike-wave complex, two to six extracellular bursts preceded the first spike-wave complex in the EEG. As far as the end of a SWD was concerned, the high-frequency burst pattern of NRT units could terminate after $(24 \%)$, at the same time as $(36 \%)$ (Fig. $1 B)$, or before $(38 \%)$ (Fig. 1A1) the last clearly defined spike-wave complex of a SWD in the EEG. In the latter case, two to five spike-wave complexes were evident in the EEG after the last extracellularly recorded high-frequency burst.

The first action potential in the high-frequency burst preceded the peak of the EEG spike component of the corresponding spike-wave complex by $18.7 \pm 10.6 \mathrm{msec}(n=450$ bursts from 9 $\mathrm{U})$ (Fig. 2A1,A2). A similar analysis conducted using all action potentials in a burst showed that the latency to the peak of the spike component was $7.4 \pm 12.7 \mathrm{msec}$ (Fig. 2A3). The duration of the high-frequency burst was $25.9 \pm 4.8 \mathrm{msec}(n=450$ from $9 \mathrm{U})$, its mean intraburst frequency was $301 \pm 48 \mathrm{~Hz}$, and the number of action potentials it contained ranged from 6 to $15(8.5 \pm 1.7$; $n=450$ ) (Figs. $1 D, F, 2 A$ ); however, bursts present at the start and end of a SWD generally contained three to five action potentials 
Figure 2. Properties of extracellularly recorded high-frequency burst firing in single NRT neurons during SWDs. A1, Latency of five bursts (from the same SWD) to the peak negativity of the spike component in the EEG (superimposed records in top trace). $A 2$ and $A 3$, Histogram (gray bars) and Gaussian-Laplace distribution (black line) show the latency $(\Delta t)$ of the first and all action potentials, respectively, in a burst to the peak negativity of the EEG spike (taken as time 0 , see $A 1)(n=450$ bursts from $9 \mathrm{U}$; bin size, $5 \mathrm{msec})$. The vast majority $(98 \%)$ of bursts start before the EEG spike $(A 2)$, and $>73 \%$ of all action potentials occur before the EEG spike $(A 3)$. B1, Instantaneous frequency plot shows the accelerating-decelerating pattern for 50 bursts from the unit shown in $A 1$. B2, Average instantaneous frequency plot for the same 50 bursts as shown in $B 1$.

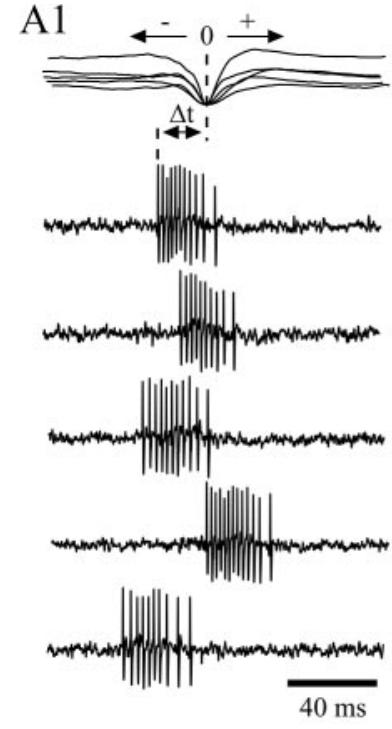

A2

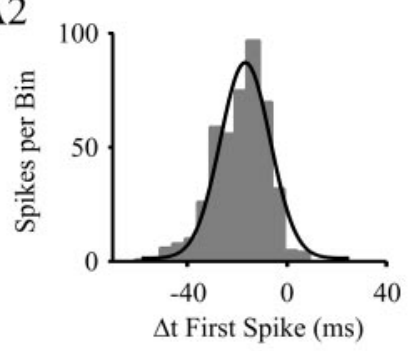

B1

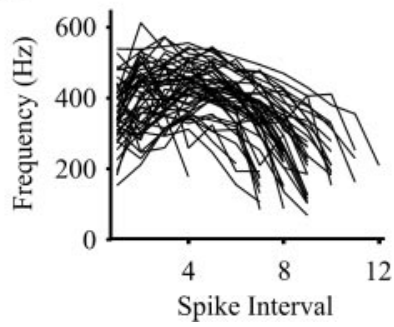

A3

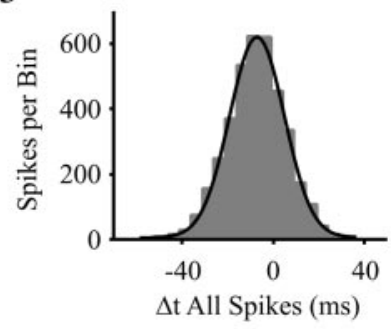

B2

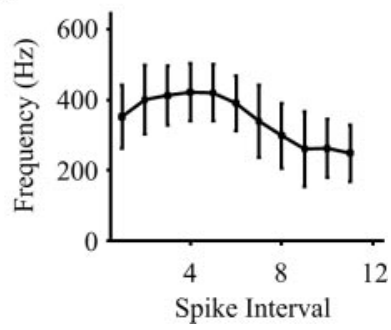

fewer than those present in the main body of a SWD. For each burst, independent of its position within a SWD, the instantaneous firing frequency showed the accelerating-decelerating pattern that is considered characteristic of a LTCP-evoked burst in NRT neurons (Mulle et al., 1986; Spreafico et al., 1988; Avanzini et al., 1989; Bal and McCormick, 1993; Contreras et al., 1993), reaching a peak value of $443 \pm 76 \mathrm{~Hz}$ (Fig. 2B1,B2).

Similar firing properties, both during and outside periods of SWDs, were confirmed in the three cases of multiunit recordings encountered in this study. In addition, these recordings highlighted how the generally random firing patterns of two neighboring NRT units in the absence of SWDs (Fig. 3A1,A2) became highly correlated with each other (Fig. $3 A 4$ ) and tightly timelocked to the spike-wave complexes (Fig. 3A3) during SWDs. These recordings also showed that the first action potential in a burst from one unit could either precede or follow the first action potential in the concomitant burst of the other unit, and on average the delay between these two action potentials was $3.4 \pm$ $7.7 \mathrm{msec}$ ( $n=150$ bursts from three double units) (Fig. $3 C$ ). It is also worth noting that at times the burst firing of a single unit ceased altogether for a variable number of spike-wave complexes, although the SWDs continued unabated in the EEG. Indeed, double-unit recordings showed that although one unit might temporarily stop firing during a SWD, the other continued its characteristic high-frequency burst pattern (Fig. 3B). For three double-unit recordings, the probability of one unit not discharging on a given spike-wave complex was $0.1 \pm 0.1$, whereas the probability of both units not discharging simultaneously was $0.05 \pm 0.05$. Finally, in both single-unit and multiunit recordings, we noticed that toward the beginning of a SWD, the highfrequency burst firing could be substituted by singlets/doublets of action potentials for a time period equivalent to four to eight spike-wave complexes (see below and Fig. 6B2,C2).

\section{Intracellular recordings: firing properties during SWDs}

The passive membrane properties of our sample of 12 NRT neurons recorded with KAc-filled electrodes included a resting membrane potential of $-57.3 \pm 6.5 \mathrm{mV}(n=12)$ and an apparent input resistance of $45 \pm 11 \mathrm{M} \Omega(n=6)$. Although no timedependent inward rectification was apparent (Mulle et al., 1986; Spreafico et al., 1988; Avanzini et al., 1989; Bal and McCormick, 1993; Contreras at al., 1993), some fast inward rectification was
A1

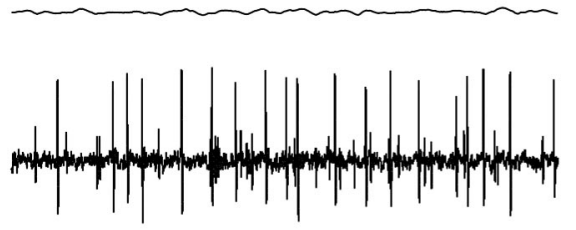

A2

A3

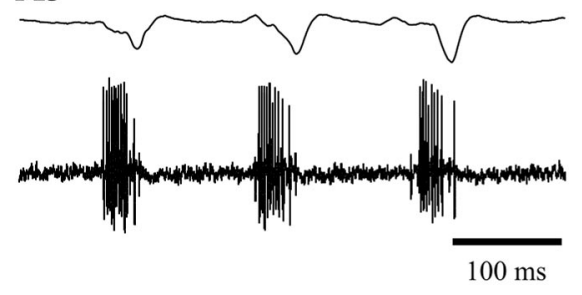

B

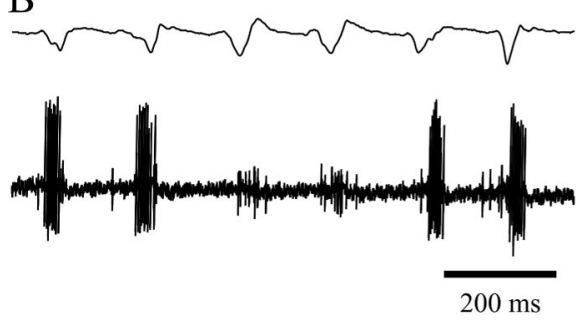

A4

$\mathrm{C}$
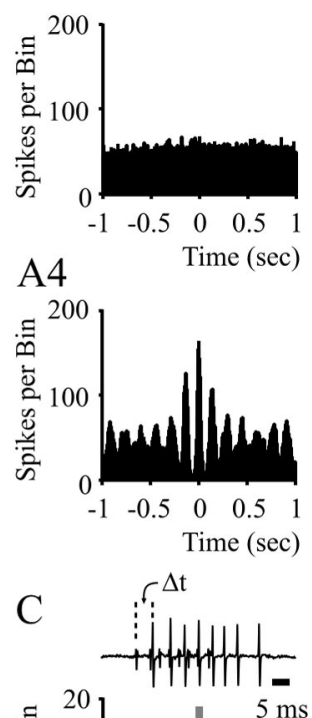

Figure 3. Firing properties in extracellular double-unit recordings during SWDs. The randomly occurring single or double action potentials in the two units $(A 1)$ become a high-frequency burst pattern, tightly correlated with the spike component of the spike-wave complexes during a SWD (A3). The synchronized firing of the two units during SWDs is evident from the comparison of the cross-correlation plots before $(A 2)$ and during (A4) SWDs (bin size, $5 \mathrm{msec} ; 0 \mathrm{sec}$ sample). $B$, Absence of burst firing in one unit during two consecutive spike-wave complexes, whereas the other unit continues unabated to show the prolonged burst firing in correspondence to the spike-wave complexes. C, Histogram (gray bars) and Gaussian-Laplace distribution (black line) show the relative timing $(\Delta t)$ between the first action potentials of concomitantly occurring bursts (see inset) in two units ( $n=150$ bursts from 3 double units; bin size, $2 \mathrm{msec}$ ). Time calibration in $A 3$ also applies to $A 1$. $A$ and $B$ are from the same double-unit recording. 
A

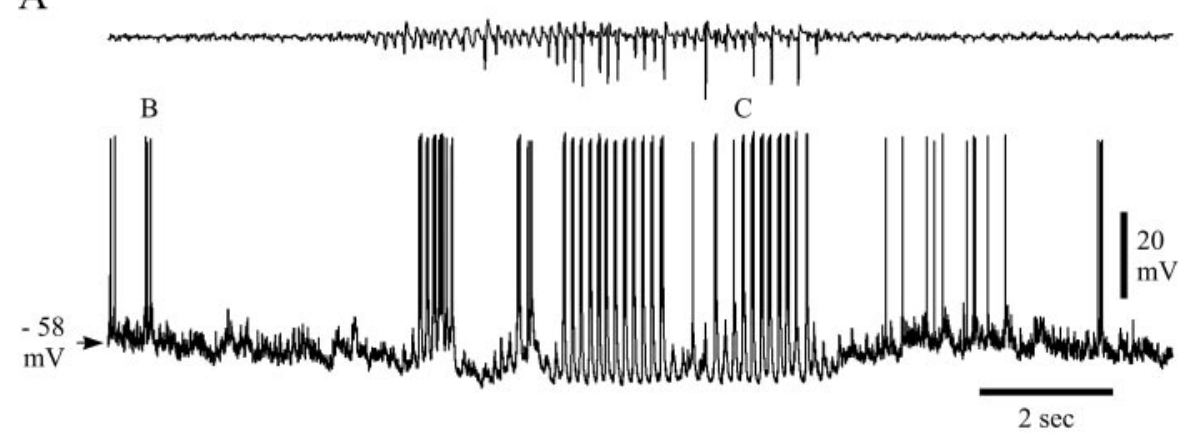

D
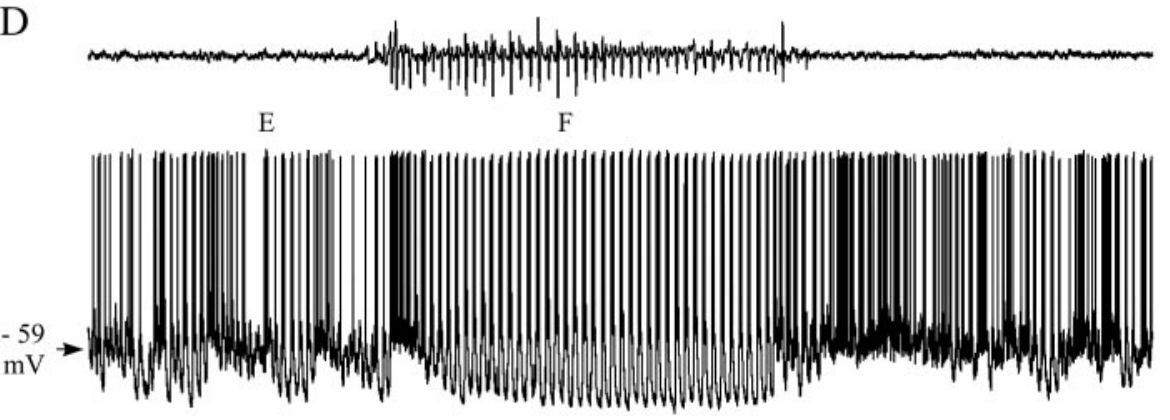

B

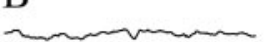

$\mathrm{C}$

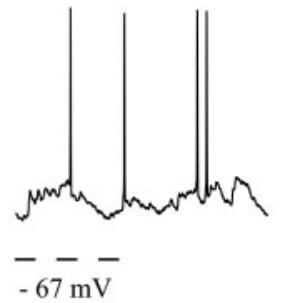

$\mathrm{E}$

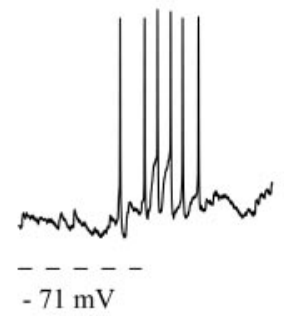

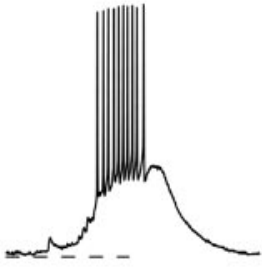

$\mathrm{F}$

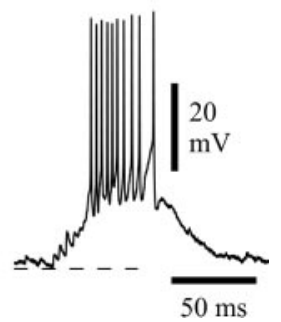

Figure 4. Intracellularly recorded activity of NRT neurons during SWDs. $A$, The occasional firing (single or double action potentials, enlarged in $B$ ) of this neuron becomes a high-frequency burst pattern (enlarged in $C$ ) during a SWD. $D$, The background firing of this neuron (a mixture of single action potentials and short, relatively low-frequency bursts) also changed to high-frequency bursts during the illustrated SWD. Marked firing before and during the SWD is enlarged in $E$ and $F$. Dashed lines in $B, C, E$, and $F$ correspond to the indicated membrane potentials. Calibrations in $A$ and $F$ also apply to $D$ and $B, C, E$, respectively.

present, as suggested by the nonlinearity of their voltage-current relationships below $-85 \mathrm{mV}$.

Analysis of the intracellularly recorded firing pattern of NRT neurons confirmed and extended the observations made during extracellular recordings. In addition, the quantitative properties of the different firing patterns observed during periods with no SWDs as well as those of the high-frequency bursts during SWDs that were recorded at resting membrane potential were remarkably similar to the corresponding values measured with extracellular electrodes (compare Fig. 10). Thus, whatever their background firing [i.e., single action potentials (Fig. 4A1,B), short bursts (with two to six action potentials) (Fig. $4 D, E$ ), or a mixture of single action potentials and short bursts], all intracellularly recorded NRT neurons switched to a firing pattern consisting exclusively of prolonged high-frequency bursts of 5-15 action potentials during a SWD $(7.7 \pm 3.1 ; n=234$ bursts from eight cells) (Fig. 4C,F). The first action potential in a burst preceded the EEG spike component by $25.3 \pm 21.9 \mathrm{msec}(n=234$ bursts from eight cells), whereas the burst duration was $28.8 \pm 13.0 \mathrm{msec}$ (compare Fig. 10B) and the mean intraburst frequency $283 \pm 72$ $\mathrm{Hz}$. The instantaneous frequency of the intracellularly recorded action potentials in a burst was also characterized by an accelerating-decelerating pattern (compare Fig. 10E) that reached a peak value of $414 \pm 69 \mathrm{~Hz}$.

\section{Intracellular recordings: evolution of the voltage waveform during a SWD}

In the majority of SWDs ( $85 \% ; n=45$ of 53 SWDs in five cells), the main intracellularly recorded component observed at the start of a SWD in the EEG was a relatively large hyperpolarization (mean, $5.6 \pm 3.8 \mathrm{mV} ; n=8$ in three cells at $-63 \mathrm{mV}$; range, $4-11$
$\mathrm{mV}$ ) (Fig. 5A1,B1, filled arrowhead). This hyperpolarization did not appear to be linked to the firing behavior that immediately preceded it; i.e., it could follow a period of silence, a few action potentials, or a short burst, indicating an unlikely contribution by a $\mathrm{Ca}^{2+}$ - and/or a $\mathrm{Na}^{+}$-dependent $\mathrm{K}^{+}$current (Avanzini et al., 1989; Bal and McCormick, 1993; Kim and McCormick, 1998). At the peak of the hyperpolarization, the first LTCP generally appeared (see below), with or without a high-frequency burst of action potentials (Fig. 5A1,B1). At more negative membrane potentials, this hyperpolarization became very small or disappeared altogether (Fig. 5A2,A3). Interestingly, a hyperpolarization with properties similar to the one present at the beginning of a SWD could also be seen without the concomitant development of a SWD in the EEG (Fig. 5B2,B3, open arrowheads). Similarly, this hyperpolarization was not linked to the firing pattern that immediately preceded it, because it could follow a period of silence (Fig. 5B2), a few action potentials (Fig. 5B3), or a short burst. The similarities between these two hyperpolarizations are highlighted by their superposition shown in Figure $5 B 1+2$ and $B 1+3$. In those SWDs in which no clear hyperpolarization could be observed at the start, the first component of the intracellularly recorded paroxysm was a small LTCP with no action potential burst.

During the early part of a SWD, and once the LTCPs and the associated high-frequency action potential bursts appeared to have been fully established, a slowly decaying depolarization could appear in the intracellular record (87\% of SWDs in five neurons). This is clearly evident from the examples shown in Figures $4 D, 6 A 1, A 2$, and $7 A$. After a few large LTCPs, the neuron depolarized (often to a more positive potential than 
A1

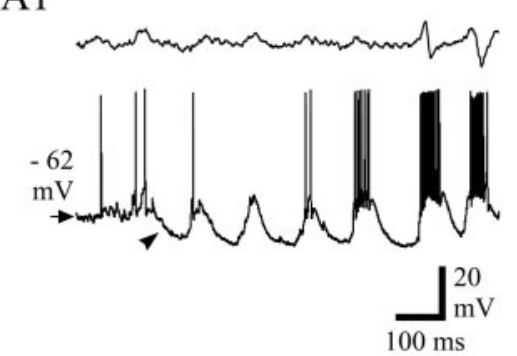

A2

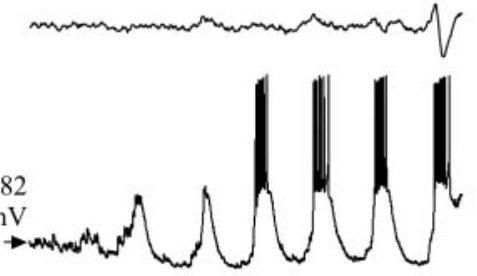

A3

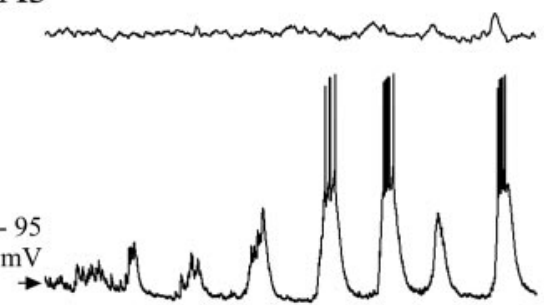

B1
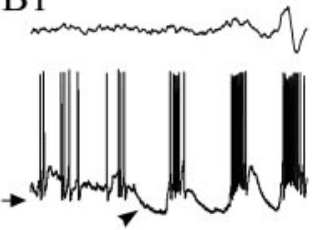

B2

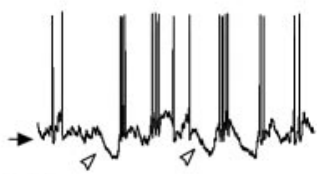

B3

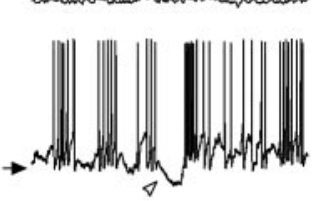

$\mathrm{B} 1+2$

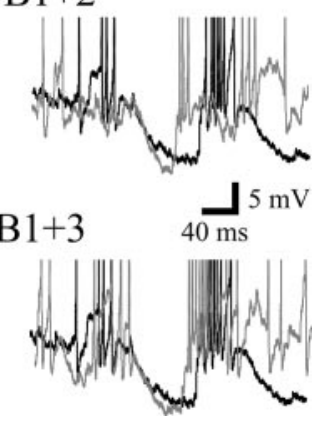

Figure 5. The start of a SWD. A1, A typical example of the start of a SWD shows a clear hyperpolarization (filled arrowhead) leading to a small-amplitude LTCP. Subsequent LTCPs quickly grow in amplitude, and prolonged bursts are evident at the same time that the first clear spike-wave complex appears in the EEG. Note that the most hyperpolarized potential during the SWD is already achieved by the trough that follows the first LTCP. Steady hyperpolarization of the neuron to -82 $\mathrm{mV}$ by $\mathrm{DC}$ injection almost abolishes this hyperpolarization (A2), whereas additional steady hyperpolarization $(A 3)$ does not produce any additional change. B1, Another example of the hyperpolarization ( filled arrowhead) that is present at the start of a SWD, where strong and prolonged burst firing is reached by the second LTCP. B2, B3, In the absence of any SWD in the EEG, hyperpolarization (open arrowhead) with properties similar to the one present at the start of the SWDs is often recorded at resting membrane potential, after either a period of electrical silence $(B 2)$ or a short low-frequency burst (B3). Superimposition of the traces in $B 1$ (black) and B2 (gray) $(B 1+2)$ and superimposition of the traces in $B 1$ (black) and $B 3$ (gray) $(B 1+3)$ highlight the similarities between the hyperpolarization that is present at the start of a SWD and the one that does not lead to any paroxysmal activity. Arrows in B1-B3 indicate $-60 \mathrm{mV}$. Action potential height in $B 1+2$ and $B 1+3$ has been truncated for clarity. Calibration in $A 1$ also applies to $A 2, A 3$, and $B 1-B 3$.

before the paroxysm), concomitantly changed its firing into singlets/doublets of action potentials or short bursts, and then slowly (1.0 $\pm 0.2 \mathrm{sec}$; range, $0.3-1.3 \mathrm{sec}$; i.e., up to eight spike-wave complexes) repolarized back, while the firing would gradually return to the pattern of rhythmic LTCPs (and associated prolonged high-frequency bursts) for the remainder of the SWD. This sequence of events occurred only once within a SWD (Fig. $4 D$ ). In a few cases, the SWD in the EEG became apparent only during this period of interruption in high-frequency bursts (Figs.
$4 D, 7 A$ ), whereas in the majority of cases, we noticed that the EEG during and before this burst firing interruption had spikewave complexes of smaller amplitude and slightly but significantly higher frequency (before, $9.4 \pm 1.3 \mathrm{~Hz}, n=12$; during, $9.4 \pm 1.0$ $\mathrm{Hz}, n=18)$ than the fully developed, main body of the SWD (7.4 $\pm 0.3 \mathrm{~Hz} ; p<0.0001$ for both) (Fig. 6 A1). A similar change in firing pattern from high-frequency bursts to either short bursts or singlets/doublets of action potentials within the early part of a SWD was also detected in single-unit extracellular recordings (Fig. 6B1,B2) and concomitantly in both units of multiunit recordings (Fig. 6C1,C2).

The intracellular paroxysm ended with a series of voltage and firing changes similar to those underlying the interruption of burst firing described above (Fig. 7A,B). Thus, the neuron would depolarize to a more positive membrane potential than before the SWD and then slowly repolarize back to the pre-SWD membrane potential (Fig. 7A,B). This depolarization was accompanied by the abolishment of LTCPs and instatement of single or double action potentials, often at a higher frequency than that present before the SWD (Fig. 7A). In $40 \%$ of SWDs ( $n=21$ of 53 in five cells), this slowly decaying depolarization was hardly detectable at resting membrane potential (although its presence could be inferred from the higher firing rate) (Fig. 7A), but it was clearly visible at slightly more negative membrane potentials (Fig. $7 B$ ). Thus, whereas the hyperpolarization present at the start of a SWD was at its maximum amplitude close to the resting membrane potential, the slowly decaying depolarization that ended a SWD was larger (9.8 $\pm 2.7 \mathrm{mV} ; n=10$ in three cells) when the neuron was slightly hyperpolarized $(-67 \mathrm{mV})$. Note that the increase in tonic firing that was present at the end of a SWD was also visible in extracellular recordings (compare Fig. 1B).

The full sequence of intracellular events occurring during a SWD (i.e., large hyperpolarization at the start, LTCPs plus high-frequency bursting, and slowly decaying depolarization at the end) could also be observed in the absence of any paroxysmal activity in the EEG (Fig. 7C1). These intracellular paroxysms that occurred in the absence of SWDs had properties (including the interburst frequency and the voltage dependence of their different components) similar to those occurring during SWDs, except for their relatively short duration (0.3-0.6 sec) (Fig. 7C1-C3). In this respect, therefore, these intracellular paroxysms that occurred in the absence of SWDs (Fig. 7C1-C3) were strikingly similar to the sequence of events occurring at the beginning of a SWD (Figs. $4 C, 7 A$ ). Note that short paroxysms (i.e., two to four high-frequency burst firings) in the absence of SWDs in the EEG were also observed during extracellular recordings (data not shown).

\section{Intracellular recordings: LTCPs and small depolarizing potentials}

As described previously, one of the striking features of the intracellular voltage waveform during SWDs was the presence of large LTCPs tightly linked to each spike-wave complex in the EEG and crowned by a prolonged burst of action potentials (Fig. $8 A 1$ ). As expected, when NRT neurons were increasingly hyperpolarized by DC injection, the LTCPs became larger in amplitude and shorter in duration (Fig. 8A2,A3). Somatic current steps that provided a time and voltage for removal of T-type $\mathrm{Ca}^{2+}$ current inactivation similar to or slightly greater than those experienced by the neuron during SWDs failed to elicit a LTCP (Fig. 8C2,C3), with much larger steps resulting in only the occasional generation of a LTCP (14 $\pm 2 \%$ of trials; $n=32$ of 458 in five cells) (Fig. 
A1

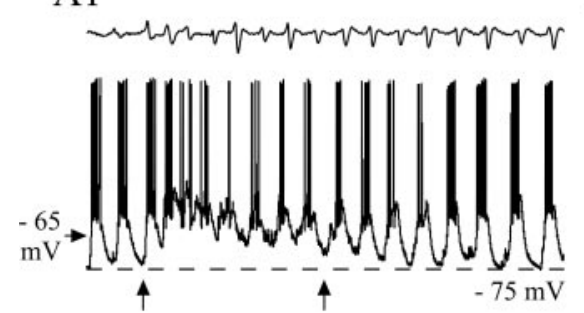

B1

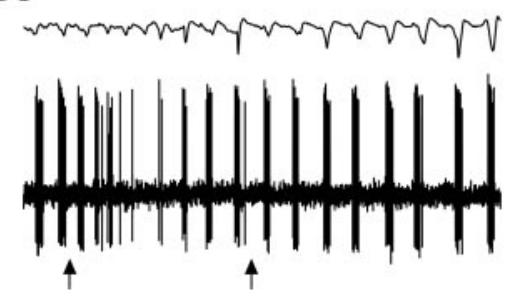

C1

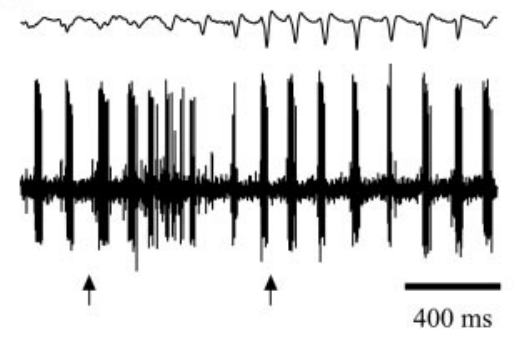

A2

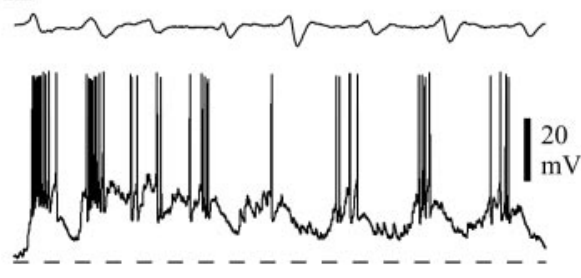

B2

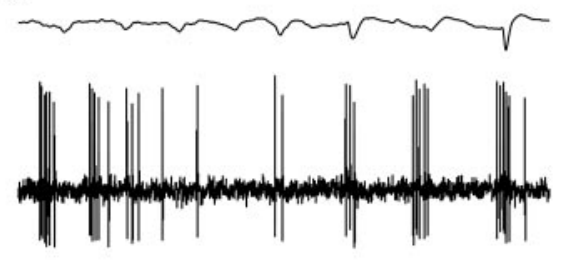

$\mathrm{C} 2$

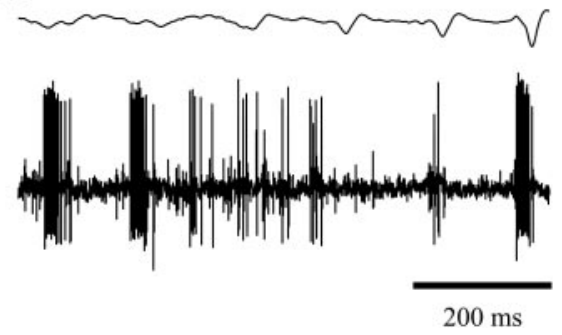

Figure 6. Interruption of high-frequency burst firing during SWDs. Intracellular $(A 1)$ and extracellular (B1, single unit; $C 1$, double unit) recordings during the early part of SWDs indicate that the characteristic high-frequency burst firing is replaced by periods of single/double action potentials or short bursts. The EEG before and during this interruption generally has a higher frequency and smaller amplitude spike-wave complexes than the fully developed paroxysm. The intracellular records $(A 1$ and $A 2)$ show that these periods of tonic/short burst firing are generated by a slowly decaying depolarization similar to the one observed at the end of a SWD (compare Fig. 7A,B). The multiunit recording in $C$ shows both units to simultaneously stop and later restart their highfrequency burst firing. $A 2, B 2$, and $C 2$ are enlargements of a portion (arrows) of $A 1, B 1$, and $C 1$, respectively. Dashed lines in $A 1$ and $A 2$ correspond to the indicated membrane potentials. Voltage calibration in $A 2$ also applies to $A 1$; time calibration in $C 1$ and $C 2$ also applies to $A 1, B 1$ and $A 2, B 2$, respectively.
$8 C 4)$; these results indicate that the origin of SWD-associated LTCPs is primarily dendritic (cf. Destexhe et al., 1996).

Whereas the decay of the LTCPs occurring during a SWD had an overall smooth appearance (Fig. $8 A, B 1$ ), their rising phase was invariably sculptured by the presence of three to nine smallamplitude (1-8 mV), high-frequency $(200-1000 \mathrm{~Hz})$ depolarizing potentials (SDPs) (Fig. $8 \mathrm{B1}$ ). In the vast majority of cases, these SDPs started during the trough present between two successive LTCPs, and thus they basically made up the depolarizing phase leading to a LTCP and associated action potential burst. Indeed, because the SDPs often summed even up to the first action potential in a burst, it was at times difficult to establish the "true" start of the LTCP along the depolarizing waveform. Interestingly, groups of SDPs similar to those leading to LTCPs during SWDs were also observed when no SWD and none of its intracellularly recorded components were present in the EEG and the intracellular voltage trace, respectively (Fig. 8B2). However, these groups of SDPs only rarely lead to the generation of a LTCP, even when recorded at hyperpolarized membrane potentials $(6.3 \pm 1.1 \%$; $n=28$ of 444 SDP groups in four cells) (Fig. 8B2).

\section{Intracellular recordings with $\mathrm{KCl}$-filled electrodes}

To test the possible participation of $\mathrm{Cl}^{-}$-dependent events in the activity of NRT neurons during SWDs, intracellular recordings were performed with KCl-filled electrodes. The morphological features of the neurons recorded with $\mathrm{KCl}$ electrodes (Fig. 9A3) were similar to those of the neurons recorded extracellularly or intracellularly with KAc electrodes. The input resistance of these cells (36 $\pm 5 \mathrm{M} \Omega ; n=3$ ) was similar to those recorded with KAc-filled electrodes, but the resting membrane potential was less negative $(-49.8 \pm 3.6 \mathrm{mV} ; n=4 ; p<0.05)$ (Figs. 9A1, $B$, $10 G)$. This was associated with a higher background firing rate $(59 \pm 38 \mathrm{~Hz})($ Fig. $9 A 1, B)$ than in neurons recorded extracellu- larly or intracellularly with KAc electrodes $(p<0.05)$ (Fig. 10F). Moreover, neurons recorded with $\mathrm{KCl}$ electrodes showed a prominent afterhyperpolarization of the action potential (compare Fig. $9 B$ with Fig. $4 B, E$ ). When measured in the absence of SWDs and at a similar membrane potential $(-52 \mathrm{mV})$, the amplitude of the afterhyperpolarization was $74 \%$ larger in NRT neurons recorded with $\mathrm{KCl}$ than $\mathrm{KAc}$ electrodes $(\mathrm{KCl}, 9.1 \pm 0.8 \mathrm{mV}, n=324$ from four cells; KAc, $5.3 \pm 2.0 \mathrm{mV}, n=571$ from six cells; $p<0.01$ ), and its time to peak was shorter $(\mathrm{KCl}, 0.76 \pm 0.26 \mathrm{msec}$; KAc, $1.28 \pm 0.29$ msec; $p<0.05)$.

A hyperpolarization $(7.9 \pm 3.1 \mathrm{mV} ; n=7$ in three cells at -63 $\mathrm{mV} ; p=0.45$ compared with KAc recordings) (Fig. 9D1,D2) and a depolarization were present at the start and end, respectively, of the SWDs recorded with $\mathrm{KCl}$ electrodes, and the firing pattern of these neurons during SWDs was also characterized by highfrequency bursts of action potentials (Fig. 9C-D2) that occurred at the same frequency as and were time-locked to the EEG spike. These high-frequency bursts (Fig. 9C,D1,E1) were generated by LTCPs, which, because of the less negative resting membrane potential of $\mathrm{KCl}$ recordings, became clearly evident only at hyperpolarized membrane potentials (Fig. 9D2,E2,E3). In addition, the waveform of the overall depolarization (i.e., SDPs plus LTCP) leading to the action potential burst (Fig. 9E1-E3) appeared broader than that in KAc recordings at similar membrane potentials (Fig. 8, compare $A 1$ and $A 3$ ).

The number of action potentials in a burst was $7.2 \pm 1.5(n=$ 107 bursts from three cells), which is similar to that observed in extracellular or KAc intracellular recordings (Fig. 10A). However, the duration of a burst was longer in recordings with $\mathrm{KCl}$ (39.1 $\pm 9.6 \mathrm{msec} ; n=107 ; p<0.05)$ (Fig. 10B), and thus the mean intraburst frequency was lower $(161 \pm 27 \mathrm{~Hz} ; n=107 ; p<$ 0.05 ) (Fig. 10C). The first action potential in a burst preceded the 
A

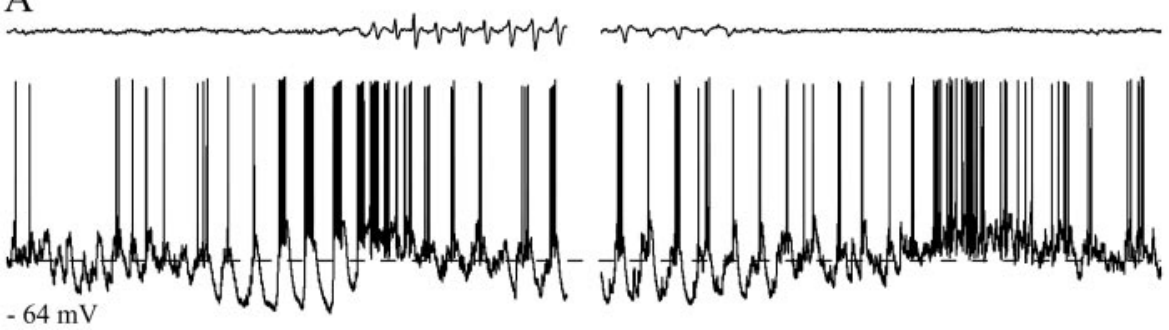

B

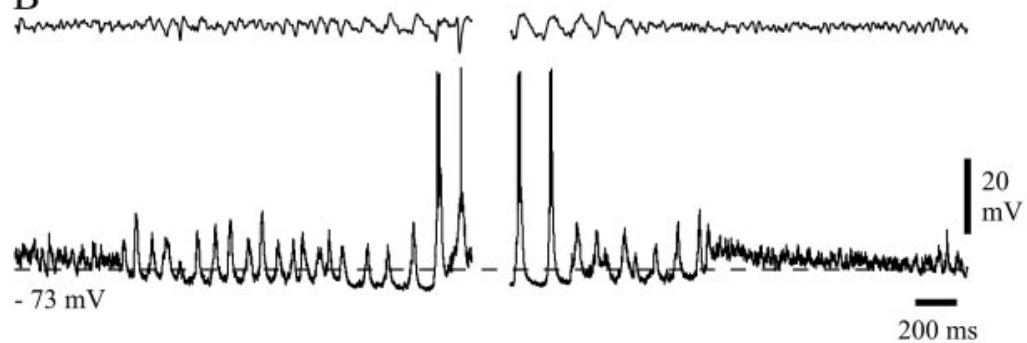

Figure 7. End of a SWD and short intracellular paroxysms in the absence of SWDs. $A, B$, Two SWDs from two neurons that had different resting membrane potentials (indicated) show that the slowly decaying depolarization is more clearly visible at more negative potentials. Note the higher firing rate of single action potentials at the end of the SWD shown in $A$. Dashed lines in $A, B$, and $C 1$ correspond to the indicated membrane potentials. $C 1$, A short intracellular paroxysm is depicted, whereas the EEG shows no SWDs. The evolution of the voltage waveform carries the same characteristics as those present during a SWD [i.e., the hyperpolarization (arrowhead) present at the start, the quick instatement of high-frequency bursts, and the higherfrequency, single action potential firing (between arrows) at the end]. The slowly decaying depolarization becomes visible when the neuron is hyperpolarized (C2), before becoming smaller with additional steady hyperpolarization $(C 3)$. Dashed lines in $C 2-C 3$ indicate the membrane potential before the intracellular paroxysm. Calibrations in $B$ also apply to $A$ and $C 1-C 3$.
C1

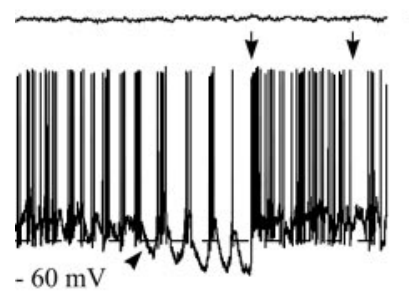

$\mathrm{C} 2$

C3
EEG spike by $31.2 \pm 20.9 \mathrm{msec}(n=107$ bursts) and thus occurred significantly earlier $(p<0.01)$ than in extracellularly or KAc intracellularly recorded neurons. The instantaneous frequency profile of a burst retained its accelerating-decelerating pattern in KCl-recorded cells, although it showed lower values for all intervals, including the peak measurement $(243 \pm 40 \mathrm{~Hz} ; n=$ $107)$, compared with cells recorded with KAc electrodes or extracellularly $(p<0.01)$ (Fig. 10D,E).

\section{DISCUSSION}

The novel findings of this intracellular analysis of NRT neurons during spontaneous, genetically determined SWDs are (1) the identification of a large-amplitude hyperpolarization at the start of a SWD; (2) the presence, during the early part of a SWD, of a short interruption of burst firing that is mediated by a slowly decaying depolarization and is accompanied by a smalleramplitude, higher-frequency EEG paroxysm; (3) the occurrence of short intracellular paroxysms in the absence of SWDs; (4) the lack of hyperpolarizing $\mathrm{GABA}_{\mathrm{A}}$ IPSPs during and in the absence of SWDs; and (5) the marked changes in background firing and SWD-associated bursts observed in recordings with $\mathrm{KCl}$ electrodes. The unmasking of these properties in the GAERS NRT confirms their unique association with spontaneous genetically determined SWDs and their probable involvement in the pathophysiological processes of CAE seizures.

\section{Firing characteristics during SWDs}

This study has enlarged the findings of previous studies in the GAERS NRT during SWDs (Seidenbecher et al., 1998; Pinault et al., 2001) by showing the following firing properties: (1) Because the SWD-associated change from tonic to burst firing could precede or follow the first EEG spike-wave complex, a NRT neuron does not have a fixed role in the generation/synchronization of SWDs within the thalamocortical loop but could be either leading or being recruited by other neurons in successive SWDs. (2) The firing of single NRT units started $\sim 19$ msec earlier than the EEG spike, and thus before the sensory thalamic nuclei [Seidenbecher et al. (1998), compare their Fig. 4]. This and the higher strength of cortical EPSPs in NRT (compared with thalamocortical) neurons (Golshani et al., 2001) explain the inhibition and low firing rate of most thalamocortical neurons during SWDs (Steriade and Contreras, 1995; Pinault et al., 1998). (3) The high probability that adjacent units will produce bursts in relation to a given spike-wave complex and the low probability than one unit alone will discharge a burst indicate that the majority of closely apposed NRT neurons will discharge at each spike-wave complex and stress the high level of synchrony between adjacent NRT neurons during SWDs (Sohal et al., 2000).

\section{Start and end of a SWD}

It seems unlikely that the hyperpolarization at the start of a SWD involves the type II metabotropic glutamate receptor (mGluR)activated $\mathrm{K}^{+}$current that is present in young NRT neurons (Cox and Sherman, 1999), because the maximum amplitude of the hyperpolarization elicited by type II mGluR agonists is only 3 $\mathrm{mV}$, and the synaptic activation of these receptors remains to be demonstrated. It is also unlikely that this hyperpolarization rep- 


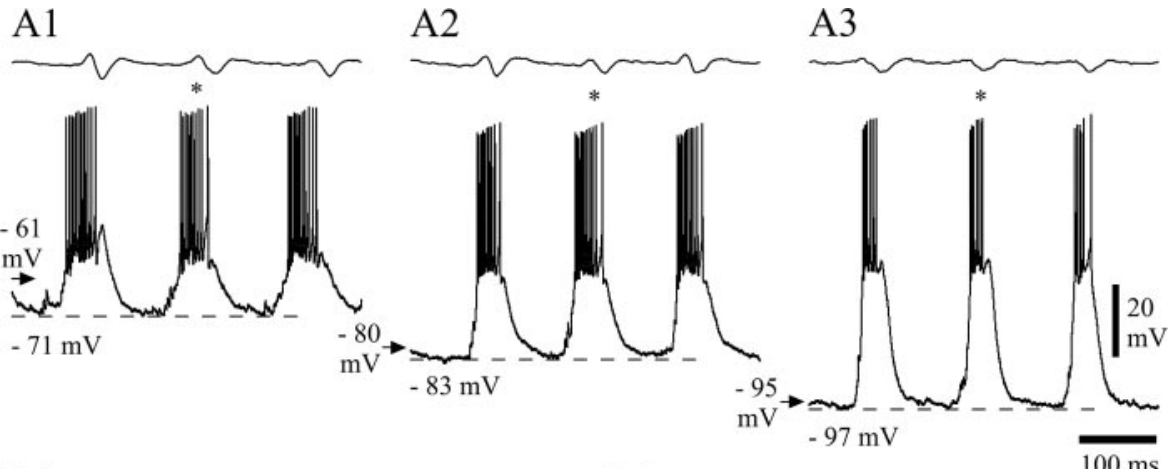

B1
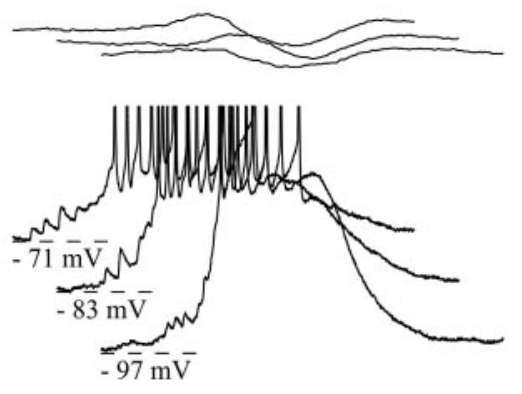

C1
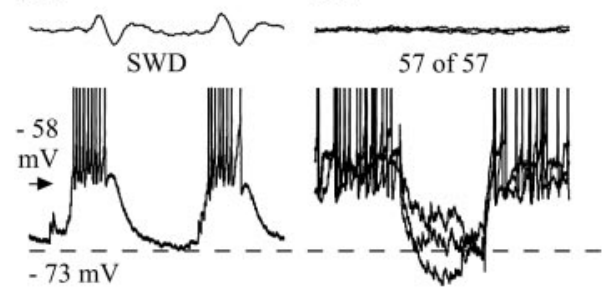

B2
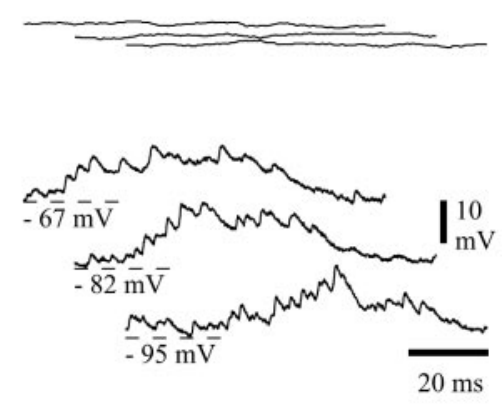

$\mathrm{C} 3$

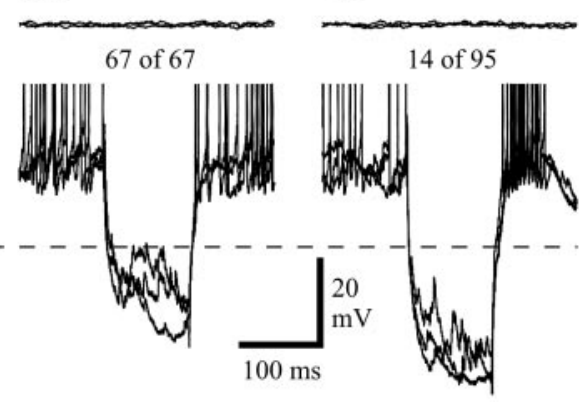

Figure 8. Properties of LTCPs during SWDs. $A$, LTCPs and associated high-frequency bursts of action potentials recorded during SWDs at resting membrane potential $(A 1)$ and at two hyperpolarized levels achieved by the injection of DC $(A 2,-0.5 \mathrm{nA} ; A 3,-1 \mathrm{nA})$ (membrane potential before the SWDs is indicated by an arrow). Note the decreased duration and increased amplitude of the LTCPs for more negative values of membrane potential (LTCPs marked by asterisks are enlarged in B1). B1, A sequence of highfrequency SDPs leads to the activation of each LTCP during SWDs. (Action potentials have been truncated for clarity.) B2, Similar groups of SDPs that do not lead, however, to the activation of LTCPs, are also observed when no SWD is present in the EEG. C1, Two successive LTCPs during a SWD recorded at resting membrane potential (arrow). C2-C4, Each panel shows three superimposed voltage responses to current steps of $-0.3 \mathrm{nA}(C 2),-0.5 \mathrm{nA}(C 3)$, and $-0.8 \mathrm{nA}$ (C4) in the absence of SWDs (same NRT neuron as in $C 1)$. Voltage excursions similar to $(C 2)$ or larger than $(C 3)$ the hyperpolarization achieved between two LTCPs during SWDs $(C 1)$ do not evoke any LTCP (number of trials indicated at the top), whereas much larger voltage responses $(C 4)$ evoke a LTCP in only 14 of 95 trials. Action potential height in $C 1-C 4$ has been truncated for clarity. Dashed lines in A1-A3, B1$B 2$, and $C 1-C 4$ correspond to the indicated membrane potentials. Calibrations in $A 3, B 2$, and $C 4$ also apply to $A 1-A 2, B 1$, and $C 1-C 3$, respectively. resents a $\mathrm{GABA}_{\mathrm{A}}$ IPSP generated by adjacent NRT neurons (Sanchez-Vives et al., 1997; Ulrich and Huguenard, 1997a), because (1) it is not composed of multiple summing events, (2) its time to peak is much longer than that of a single GABA IPSP $_{A}$ in NRT neurons (Zhang et al., 1997), (3) it did not reverse in polarity within the range of reversal potentials $(-68$ to $-76 \mathrm{mV})$

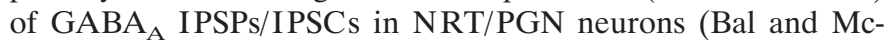
Cormick, 1993; Sanchez-Vives et al., 1997; Ulrich and Huguenard 1997a,b; Bazhenov et al., 1999), and (4) it was unaffected by recording with $\mathrm{KCl}$ electrodes.

Conversely, the waveform of the hyperpolarization was remarkably similar to that of the hyperpolarization generated by the switching off of the window component of the T-type $\mathrm{Ca}^{2+}$ current in thalamocortical [Williams et al. (1997), their Fig. 6 $A$; Hughes et al. (1999), their Fig. 3A] and PGN [Steriade et al. (1997), their Fig. 4.8A] neurons. This possibility is supported by the findings that the T-type $\mathrm{Ca}^{2+}$ channel subunit $(\alpha 1 \mathrm{I})$, which is preferentially expressed in NRT neurons (Lee et al., 1999; Talley et al., 2000), generates a larger window current than $\alpha 1 \mathrm{G}$ or $\alpha 1 \mathrm{H}$ (Klockner et al., 1999), and that the T-type $\mathrm{Ca}^{2+}$ current in GAERS NRT neurons is larger than in nonepileptic control rats (Tsakiridou et al., 1995). The hyperpolarization present at the start of a SWD also shares striking similarities with $\mathrm{GABA}_{\mathrm{B}}$ IPSPs in PGN neurons [Sanchez-Vives et al. (1997), their Fig.
$5 B]$, although in ferrets and rats, synaptic activation of these receptors is restricted to only $40 \%$ and $17 \%$, respectively, of PGN/NRT neurons (Ulrich and Huguenard, 1996; SanchezVives et al., 1997). Because a higher expression of $\mathrm{GABA}_{\mathrm{B}}$ receptor mRNA is present in the GAERS NRT compared with in nonepileptic control rats (Depaulis et al., 2000), however, it might be possible that most GAERS NRT neurons have functional $\mathrm{GABA}_{\mathrm{B}}$ receptors that mediate this hyperpolarization.

As far as the slowly decaying depolarization observed at the end of a SWD is concerned, its properties (i.e., waveform, voltage dependence, and insensitivity to somatic $\mathrm{Cl}^{-}$injection) are similar to those of the slow afterdepolarization of guinea pig NRT neurons (Bal and McCormick, 1993), and therefore a $\mathrm{Ca}^{2+}$ activated, nonselective cation current is likely to mediate the termination of genetically determined SWDs.

\section{Intracellular paroxysms in the absence of SWDs and interruption of high-frequency burst firing during a SWD}

Because the burst firing interruption appeared only within the early part of a SWD, it might indicate that single and adjacent NRT neurons are attempting to exit from, or to stop the spreading of, a developing seizure (cf. Sohal et al., 2000). The similarities in voltage waveform and frequency between the early part of a SWD 


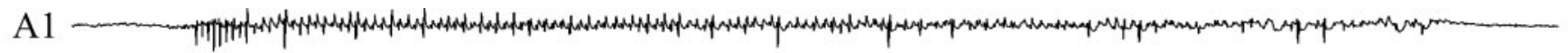

B D1

E1 C
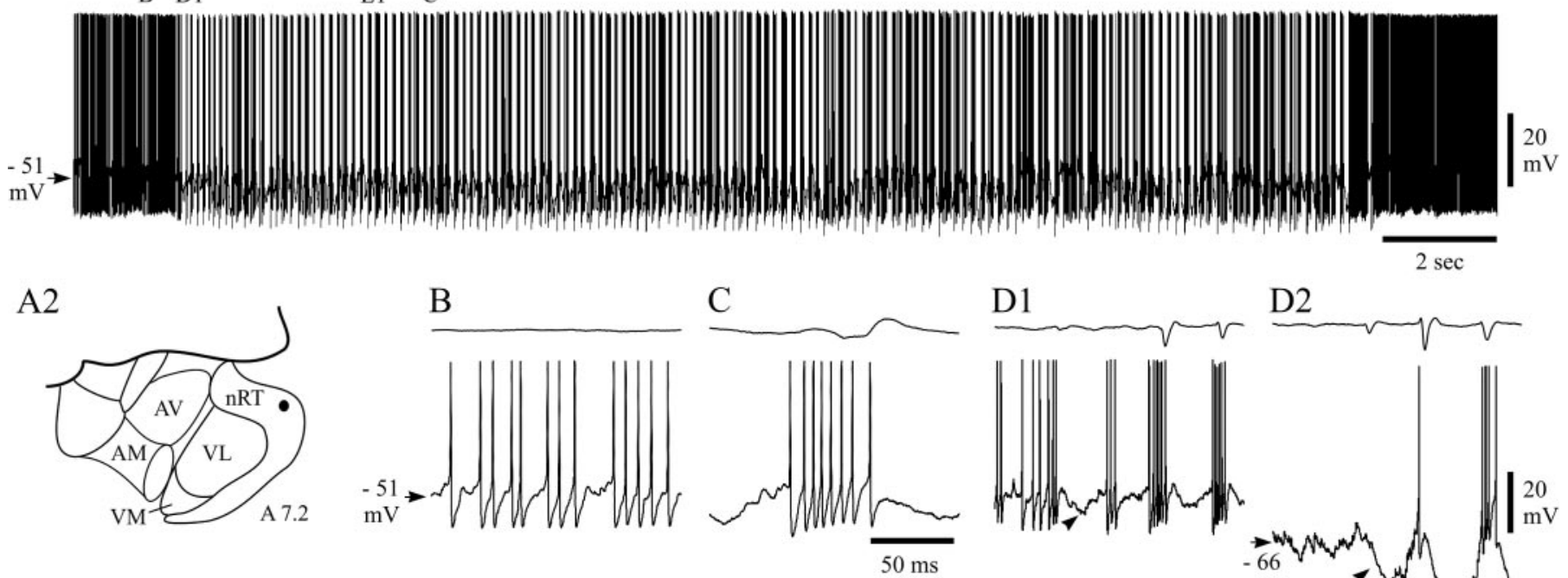

D1

D2

A3

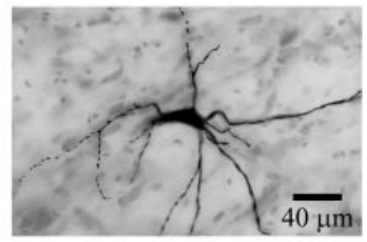

E1

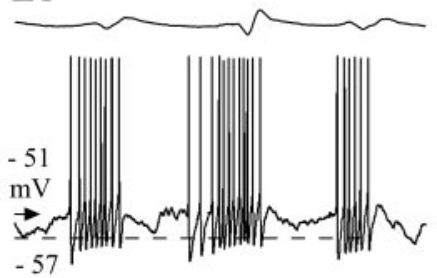

$\mathrm{mV}$
E2

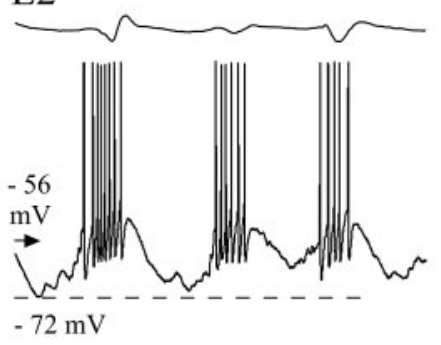

E3

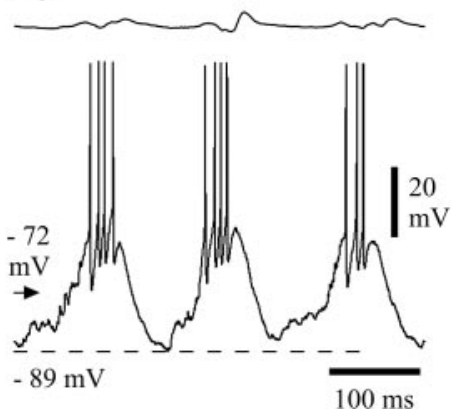

Figure 9. Activity of NRT neurons recorded intracellularly with KCl-filled electrodes. A1, Compared with the recordings with KAc electrodes (Fig. 5), NRT neurons recorded with $\mathrm{KCl}$ electrodes had a more depolarized resting membrane potential (arrow) and a much stronger background firing ( $B$ ). During SWDs, the bursts of action potentials $(C)$ had a lower frequency than those observed with KAc electrodes. Marked periods are enlarged in $B$, $C, D 1$, and $E 1$ below. A2, Schematic horizontal plane drawing showing the position ( filled circle) of the NRT neuron from which the activity in $A 1$ was recorded. $A M$, Anteromedial thalamic nucleus; $A V$, anteroventral thalamic nucleus; $n R T$, thalamic reticular nucleus; $V L$, ventrolateral thalamic nucleus; $V M$, ventromedial thalamic nucleus (anteriority relative to the interaural line is indicated). A3, Photomicrograph of the neurobiotin-injected NRT neuron in $A 2$. Note the typical fusiform perikaryon and numerous varicose dendrites. D1, D2, Hyperpolarization (arrowheads) could be detected at the start of a SWD during recordings with $\mathrm{KCl}$ electrodes, both at resting $(D 1)$ and hyperpolarized $(D 2)(-1.3 \mathrm{nA})$ membrane potentials. The smaller size of the hyperpolarization at potentials greater than $-60 \mathrm{mV}$ was not peculiar to $\mathrm{KCl}$ recordings. E1-E3, LTCPs and associated bursts of action potentials recorded during SWD at resting membrane potential $(E 1)$ and at two hyperpolarized levels achieved by injection of $-0.5 \mathrm{nA}(E 2)$ and $-1.3 \mathrm{nA}(E 3)$ (membrane potential before the SWDs is indicated by an arrow). As in KAc recordings (Fig. 8), the LTCPs become larger in amplitude with steady hyperpolarization. The resting membrane potential indicated in $B$ (arrow) also applies to $C$ and D1. Dashed lines in E1-E3 correspond to the indicated membrane potentials. Voltage calibration in $D 2$ also applies to $B, C$, and $D 1$. Time calibration in $C$ and $D 2$ also applies to $B$ and $D 1$, respectively. Calibrations in E3 also apply to E1 and E2.

(compare Fig. $7 A$ ) and the short intracellular paroxysms occurring in the absence of SWDs (compare Fig. 7C1-C3), however, suggest an alternative possibility (i.e., that these two sequences of intracellular events represent the same NRT phenomenon, although they are associated with different levels of cortical synchrony). In other words, a short NRT paroxysm would either appear in isolation when the degree of cortical synchronization is minimal (i.e., no SWD is evident in the EEG) or develop into a full SWD when cortical synchrony is higher (i.e., a SWD is or soon becomes evident in the EEG). Note that the higher frequency in the initial stage of an EEG paroxysm is also reflected in intracellular recordings of thalamocortical and layer $\mathrm{V}$ cortical neurons [Charpier et al. (1999), their Figs. 1C, 2A] (together with layer III/VI cells; our unpublished observations). While all of these neurons slowly de- celerate their membrane potential oscillations and firing discharges down to the main frequency of the SWD without any other change in voltage waveform or firing pattern, NRT neurons show a characteristic burst firing interruption at the time of transition to the lower frequency. This suggests that NRT neurons might be implicated in phase resetting and/or strengthening of the paroxysmal activity to achieve a higher synchronization of all elements of the thalamocortical loop to the preferred frequency of the GAERS paroxysm. Because a similarly higher EEG frequency is present in the early part of a SWD in freely moving GAERS (Pinault et al., 2001) and in absence epilepsy patients (Panayiotopoulos, 1997), our data provide the first evidence of the membrane voltage and firing changes in a neuronal element of the thalamocortical loop that are associated with the gradual development of a SWD. 


\section{Bursts during SWDs}

A
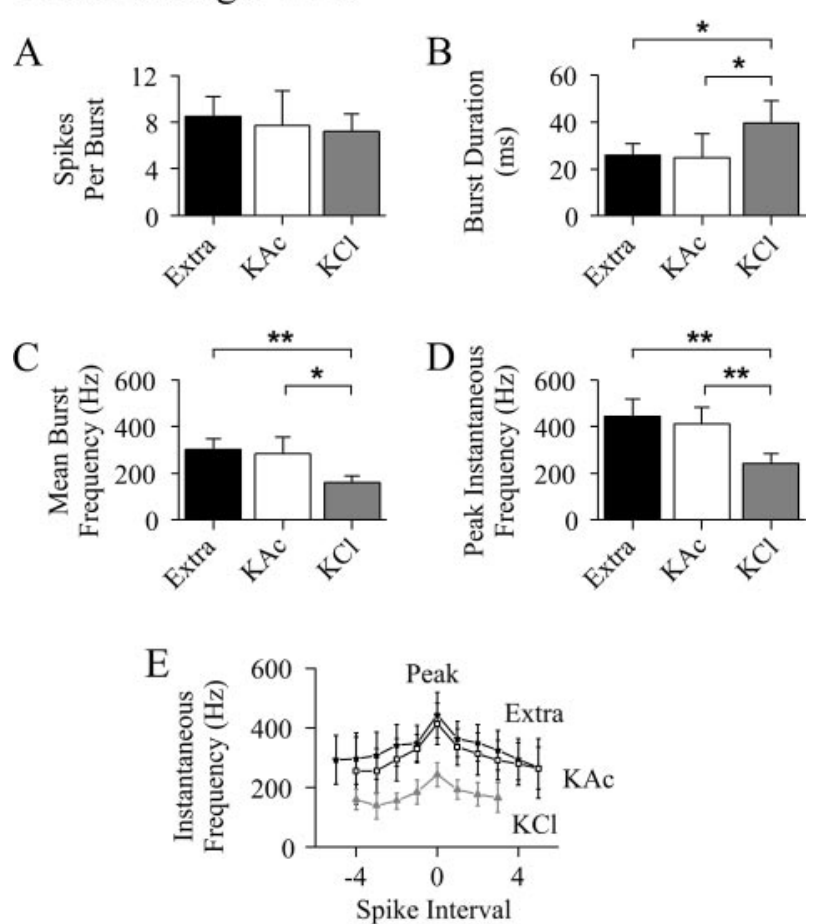

\section{No SWDs}
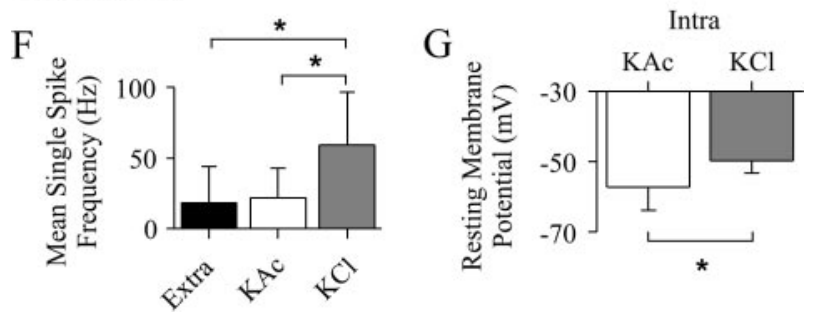

Figure 10. Comparison of NRT neuron firing recorded extracellularly and intracellularly with KAc- and KCl-filled electrodes. $A-D$, Properties (as indicated) of burst firing during SWDs (extracellular, $n=450$ bursts from $9 \mathrm{U}$; KAc, $n=234$ bursts from $8 \mathrm{U}$; KCl, $n=107$ bursts from $3 \mathrm{U}$ ). $E$, The instantaneous burst firing frequency (plotted by aligning the peak frequency of each burst to spike interval zero) is lower in bursts from $\mathrm{KCl}$ recordings (gray triangles) than KAc recordings (open squares) and extracellular recordings ( filled stars) (number of observations as in $A-D$ ). Note the greater rate of change in frequency for the intervals just before and after the peak value, in particular for the KAc and extracellular recordings. $F$, Single action potential firing in the absence of SWDs (extracellular, $n=9$; KAc, $n=7 ; \mathrm{KCl}, n=3)$. $G$, Resting membrane potential measured in the absence of SWDs (KAc, $n=12$; KCl, $n=4$ ). ${ }^{*} p<0.05$; $* * p<0.01$.

\section{Synaptic potentials}

The lack of hyperpolarizing GABA $_{A}$ IPSPs in GAERS NRT neurons either during or in the absence of SWDs supports previous suggestions of a preferential shunting mode of intra-NRT $\mathrm{GABA}_{\mathrm{A}}$-mediated inhibition (Sanchez-Vives et al., 1997; Ulrich and Huguenard, 1997a). In addition, because no other $\mathrm{Cl}^{-}$dependent current but the one activated by $\mathrm{GABA}_{\mathrm{A}}$ receptors has been described in NRT neurons, the decrease in resting membrane potential (and associated increase in background firing) and the changes in SWD-associated burst firing that were observed with KCl-filled electrodes provide the first evidence that spontaneous genetically determined SWDs occur in the presence of intra-NRT shunting inhibition. Conversely, recent genetic evidence from CAE pedigrees has highlighted some $\mathrm{GABA}_{\mathrm{A}}$ subunit abnormalities (Feucht et al., 1999; Baulac et al., 2001; Wallace et al., 2001), and a transgenic model with NRTselective impairment of the GABA system shows an increased prevalence of synchronized thalamic oscillations (Huntsman et al., 1999). Whether the lack of hyperpolarizing GABA $_{A}$ IPSPs and/or a putative weaker shunting inhibition represent a contributing factor in the generation of SWDs in GAERS must await the results of appropriate comparative studies in the nonepileptic control rat strain.

It is unlikely that the SDPs that lead to the generation of

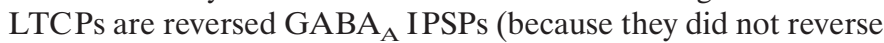
in polarity at potentials greater than $-70 \mathrm{mV}$ ) or EPSPs originating from thalamocortical neurons (cf. Bal et al., 1995a) (because during SWDs in vivo these neurons are mainly silent or occasionally fire one to three action potentials) (Steriade and Contreras, 1995; Pinault et al., 1998). Instead, the SDPs might represent primarily cortical EPSPs, because of the higher strength of this input to NRT (compared with thalamocortical) neurons (Golshani et al., 2001) and the suggested leading role of the cortex over the thalamus in absence-like paroxysms (Neckelmann et al., 1998). Alternatively, as indirectly supported by their high frequency, the SDPs might represent gap junction potentials generated by connexin-immunopositive NRT neurons (Belluardo et al., 2000; Condorelli et al., 2000), although their presence has so far been elucidated only in young rats (Landisman et al., 2000).

\section{REFERENCES}

Avanzini G, de Curtis M, Panzica F, Spreafico R (1989) Intrinsic properties of nucleus reticularis thalami neurones of the rat studied in vitro. J Physiol (Lond) 416:111-122.

Avanzini G, Vergnes M, Spreafico R, Marescaux C (1993) Calciumdependent regulation of genetically determined spike and waves by the reticular thalamic nucleus of rats. Epilepsia 34:1-7.

Avoli M, Gloor P, Kostopoulos G, Naquet R (1990) Generalized epilepsy: neurobiological approaches. London: Birkhäuser.

Avoli M, Rogawski MA, Avanzini G (2001) Generalized epileptic disorders: an update. Epilepsia 42:445-457.

Bal T, McCormick DA (1993) Mechanisms of oscillatory activity in guinea-pig nucleus reticularis thalami in vitro: a mammalian pacemaker. J Physiol (Lond) 468:669-691.

Bal T, von Krosigk M, McCormick DA (1995a) Synaptic and membrane mechanisms underlying synchronized oscillations in the ferret lateral geniculate nucleus in vitro. J Physiol (Lond) 483:641-663.

$\mathrm{Bal}$ T, von Krosigk M, McCormick DA (1995b) Role of the ferret perigeniculate nucleus in the generation of synchronized oscillations in vitro. J Physiol (Lond) 483:665-685.

Bal T, Debay D, Destexhe A (2000) Cortical feedback controls the frequency and synchrony of oscillations in the visual thalamus. J Neurosci 20:7478-7488.

Baulac S, Huberfeld G, Gourfinkel-An I, Mitropoulou G, Beranger A, Prud'homme JF, Baulac M, Brice A, Bruzzone R, LeGuern E (2001) First genetic evidence of $\mathrm{GABA}_{\mathrm{A}}$ receptor dysfunction in epilepsy: a mutation in the gamma2-subunit gene. Nat Genet 28:46-48.

Bazhenov M, Timofeev I, Steriade M, Sejnowski TJ (1999) Selfsustained rhythmic activity in the thalamic reticular nucleus mediated by depolarizing $\mathrm{GABA}_{\mathrm{A}}$ receptor potentials. Nat Neurosci 2:168-174.

Belluardo N, Mud G, Trovato-Salinaro A, Le Gurun S, Charollais A, Serre-Beinier V, Amato G, Haefliger JA, Meda P, Condorelli DF (2000) Expression of connexin36 in the adult and developing rat brain. Brain Res 865:121-138.

Blumenfeld H, McCormick DA (2000) Corticothalamic inputs control the pattern of activity generated in thalamocortical networks. J Neurosci 20:5153-5162.

Charpier S, Leresche N, Deniau JM, Mahon S, Hughes SW, Crunelli V (1999) On the putative contribution of $\mathrm{GABA}_{\mathrm{B}}$ receptors to the electrical events occurring during spontaneous spike and wave discharges. Neuropharmacology 38:1699-1706.

Condorelli DF, Belluardo N, Trovato-Salinaro A, Mudo G (2000) Expression of Cx36 in mammalian neurons. Brain Res Brain Res Rev 32:72-85.

Contreras D, Curro Dossi R, Steriade M (1993). Electrophysiological properties of cat reticular thalamic neurones in vivo. J Physiol (Lond) 470:273-294. 
Cox CL, Sherman SM (1999) Glutamate inhibits thalamic reticular neurons. J Neurosci 19:6694-6699.

Depaulis A, Leonhard-Pozza S, Marescaux C, Bischoff S (2000) Differential expression of $\mathrm{GABA}_{\mathrm{B}}$ receptor subunits mRNA in thalamic nuclei of genetic absence epilepsy rats of Strasbourg (GAERS). Soc Neurosci Abstr 26:622.3.

Destexhe A, Contreras D, Steriade M, Sejnowski TJ, Huguenard JR (1996) In vivo, in vitro, and computational analysis of dendritic calcium currents in thalamic reticular neurons. J Neurosci 16:169-185.

Feucht M, Fuchs K, Pichlbauer E, Hornik K, Scharfetter J, Goessler R, Fureder T, Cvetkovic N, Sieghart W, Kasper S, Aschauer H (1999) Possible association between childhood absence epilepsy and the gene encoding GABRB3. Biol Psychiatry 46:997-1002.

Flecknell P (1996) Laboratory animals anaesthesia. London: Academic.

Golshani P, Liu XB, Jones EG (2001) Differences in quantal amplitude reflect GluR4-subunit number at corticothalamic synapses on two populations of thalamic neurons. Proc Natl Acad Sci USA 98:4172-4177.

Hosford DA, Clark S, Cao Z, Wilson Jr WA, Lin FH, Morrisett RA, Huin A (1992) The role of $\mathrm{GABA}_{\mathrm{B}}$ receptor activation in absence seizures of lethargic (lh/lh) mice. Science 257:398-401.

Hughes SW, Cope DW, Toth TI, Williams SR, Crunelli V (1999) All thalamocortical neurones possess a T-type $\mathrm{Ca}^{2+}$ "window" current that enables the expression of bistability-mediated activities. J Physiol (Lond) 517:805-815.

Huntsman MM, Porcello DM, Homanics GE, DeLorey TM, Huguenard JR (1999) Reciprocal inhibitory connections and network synchrony in the mammalian thalamus. Science 283:541-543.

Kim U, McCormick DA (1998) Functional and ionic properties of a slow afterhyperpolarization in ferret perigeniculate neurons in vitro. J Neurophysiol 80:1222-1235.

Klockner U, Lee JH, Cribbs LL, Daud A, Hescheler J, Pereverzev A, Perez-Reyes E, Schneider T (1999) Comparison of the $\mathrm{Ca}^{2+}$ currents induced by expression of three cloned alpha1 subunits, alpha1G, alpha1H and alpha1I, of low-voltage-activated T-type $\mathrm{Ca}^{2+}$ channels. Eur J Neurosci 11:4171-4178.

Landisman CE, Beierlein M, Connors BW (2000) Electrical synapses between thalamic reticular neurons. Soc Neurosci Abstr 26:308.13.

Lee JH, Daud AN, Cribbs LL, Lacerda AE, Pereverzev A, Klockner U, Schneider T, Perez-Reyes E (1999) Cloning and expression of a novel member of the low voltage-activated T-type calcium channel family. J Neurosci 19:1912-1921.

Liu Z, Vergnes M, Depaulis A, Marescaux C (1992) Involvement of intrathalamic $\mathrm{GABA}_{\mathrm{B}}$ neurotransmission in the control of absence seizures in the rat. Neuroscience 48:87-93.

Mailly P, Charpier S, Mahon S, Menetrey A, Thierry AM, Glowinski J, Deniau J-M (2001) Dendritic arborizations of the rat substantia nigra pars reticulata neurons: spatial organization and relation to the lamellar compartmentation of striato-nigral projections. J Neurosci 21:6874-6888.

Marescaux C, Vergnes M, Depaulis A (1992) Genetic absence epilepsy in rats from Strasbourg: a review. J Neural Transm Suppl 35:37-69.

Mulle C, Madariaga A, Deschenes M (1986) Morphology and electrophysiological properties of reticularis thalami neurons in cat: in vivo study of a thalamic pacemaker. J Neurosci 6:2134-2145.

Neckelmann D, Amzica F, Steriade M (1998) Spike-wave complexes and fast components of cortically generated seizures. III. Synchronizing mechanisms. J Neurophysiol 80:1480-1494.

Ohara PT, Lieberman AR (1985) The thalamic reticular nucleus of the adult rat: experimental anatomical studies. J Neurocytol 14:365-411.

Panayiotopoulos CP (1997) Absences epilepsies. In: Epilepsy: a comprehensive textbook (Engel Jr J, Pedley TA, eds), pp 2327-2346. Philadelphia: Lippincott-Raven.

Paxinos G, Watson C (1986) The rat brain in stereotaxic coordinates, Ed 2. London: Academic.

Pinault D (1996) A novel single-cell staining procedure performed in vivo under electrophysiological control: morpho-functional features of juxtacellularly labeled thalamic cells and other central neurons with biocytin or neurobiotin. J Neurosci Methods 65:113-136.

Pinault D, Leresche N, Charpier S, Deniau JM, Marescaux C, Vergnes M, Crunelli V (1998) Intracellular recordings in thalamic neurones dur- ing spontaneous spike and wave discharges in rats with absence epilepsy. J Physiol (Lond) 509:449-456.

Pinault D, Vergnes M, Marescaux C (2001) Medium-voltage 5-9-Hz oscillations give rise to spike-and-wave discharges in a genetic model of absence epilepsy: in vivo dual extracellular recording of thalamic relay and reticular neurons. Neuroscience 105:181-201.

Sanchez-Vives MV, Bal T, McCormick DA (1997) Inhibitory interactions between perigeniculate GABAergic neurons. J Neurosci 17:8894-8908.

Seidenbecher T, Pape HC (2001) Contribution of intralaminar thalamic nuclei to spike-and-wave-discharge during spontaneous seizures in a genetic rat model of absence epilepsy. Eur J Neurosci 13:1537-1546.

Seidenbecher T, Staak R, Pape HC (1998) Relations between cortical and thalamic cellular activities during absence seizures in rats. Eur J Neurosci 10:1103-1112.

Slaght SJ, Charpier S, Deniau J-M, Leresche N, Crunelli V (2000) In vivo intracellular recordings in neurons of the nucleus reticularis thalami during spike and wave discharges in the GAERS genetic model of absence epilepsy. Soc Neurosci Abstr 26:274.2.

Snead OC (1992) Evidence for $\mathrm{GABA}_{\mathrm{B}}$-mediated mechanisms in experimental generalized absence seizures. Eur J Pharmacol 213:343-349.

Snead OC (1995) Basic mechanisms of generalized absence seizures. Ann Neurol 37:146-157.

Sohal VS, Huntsman MM, Huguenard JR (2000) Reciprocal inhibitory connections regulate the spatiotemporal properties of intrathalamic oscillations. J Neurosci 20:1735-1745.

Spreafico R, de Curtis M, Frassoni C, Avanzini G (1988) Electrophysiological characteristics of morphologically identified reticular thalamic neurons from rat slices. Neuroscience 27:629-638.

Steriade M, Contreras D (1995) Relations between cortical and thalamic cellular events during transition from sleep patterns to paroxysmal activity. J Neurosci 15:623-642.

Steriade M, Contreras D (1998) Spike-wave complexes and fast components of cortically generated seizures. I. Role of neocortex and thalamus. J Neurophysiol 80:1439-1455.

Steriade M, Jones EG, McCormick DA (1997) Thalamus: organization and function. Oxford: Elsevier Science.

Steriade M, Amzica F, Neckelmann D, Timofeev I (1998) Spike-wave complexes and fast components of cortically generated seizures. II Extra- and intracellular patterns. J Neurophysiol 80:1456-1479.

Talley EM, Solorzano G, Depaulis A, Perez-Reyes E, Bayliss DA (2000) Low-voltage-activated calcium channel subunit expression in a genetic model of absence epilepsy in the rat. Brain Res Mol Brain Res 75:159-165.

Timofeev I, Grenier F, Steriade M (1998) Spike-wave complexes and fast components of cortically generated seizures. IV. Paroxysmal fast runs in cortical and thalamic neurons. J Neurophysiol 80:1495-1513.

Tsakiridou E, Bertollini L, de Curtis M, Avanzini G, Pape HC (1995) Selective increase in T-type calcium conductance of reticular thalamic neurons in a rat model of absence epilepsy. J Neurosci 15:3110-3117.

Ulrich D, Huguenard JR (1996) $\mathrm{GABA}_{\mathrm{B}}$ receptor-mediated responses in GABAergic projection neurones of rat nucleus reticularis thalami in vitro. J Physiol (Lond) 493:845-854.

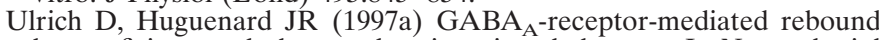
burst firing and burst shunting in thalamus. $J$ Neurophysio 78:1748-1751.

Ulrich D, Huguenard JR (1997b) Nucleus-specific chloride homeostasis in rat thalamus. J Neurosci 17:2348-2354.

Wallace RH, Marini C, Petrou S, Harkin LA, Bowser DN, Panchal RG, Williams DA, Sutherland GR, Mulley JC, Scheffer IE, Berkovic SF (2001) Mutant $\mathrm{GABA}_{\mathrm{A}}$ receptor gamma2-subunit in childhood absence epilepsy, febrile seizures. Nat Genet 28:49-52.

Williams SR, Toth TI, Turner JP, Hughes SW, Crunelli V (1997) The "window" component of the low threshold $\mathrm{Ca}^{2+}$ current produces input signal amplification and bistability in cat and rat thalamocortical neurones. J Physiol (Lond) 505:689-705.

Zhang SJ, Huguenard JR, Prince DA (1997) GABA $_{\mathrm{A}}$ receptormediated $\mathrm{Cl}^{-}$currents in rat thalamic reticular and relay neurons. J Neurophysiol 78:2280-2286. 